\title{
A Total of 2,657 Reported Cases and 14 Deaths Due to Hemorrhagic Fever with Renal Syndrome - Shaanxi Province, China, January 1-December 19, 2021
}

\author{
Jing Wei ${ }^{1, x}$; Xiaoxia Huang ${ }^{2, x}$; Shen $\mathrm{Li}^{1}$; Shanshan $\mathrm{Du}^{2}$; Pengbo $\mathrm{Yu}^{1, * ;}$; Jiandong $\mathrm{Li}^{2, * t}$
}

Hemorrhagic fever with renal syndrome (HFRS) is a group of illnesses that are caused by hantaviruses. Although increased exposure to rodents or their urine and droppings could be a decisive factor of the increasing in incidence, further research is still needed to elucidate the causes of the epidemic (1).

Since October 2021, the number of reported cases of HFRS has been increasing rapidly in Shaanxi Province. As of December 19, 2021, a total of 2,657 cases were reported with 14 deaths, $35.84 \%$ more than that in 2020 (2,051 cases and 3 deaths). Furthermore, in 2020, there were 8,121 cases and 48 deaths nationwide for morbidity and mortality rates of 0.5785 and 0.0034 per 100,000 population, and a case-fatality rate of $0.59 \%$. In all reported cases, $7.56 \%$ were aged $1-14$ years, $67.11 \%$ aged $15-59$ years, and $25.29 \%$ aged over 60 years. Compared to 2020, student cases ( 272 cases) had increased in proportion from $9.00 \%$ in 2020 to about $10.24 \%$ in 2021 , and farmer cases continued to comprise the largest proportion from about $70 \%$ in 2020 to about $66.58 \%$ in 2021.

Shaanxi Province had been recognized as an endemic area since an outbreak of HFRS was found on the north slope of Qinling Mountains in 1955 (2). In 2021 , of the 2,657 cases reported in the 10 affected cities, $2,522(94.92 \%)$ cases were from 4 cities: Xi'an $(1,553,58.45 \%)$, Weinan $(475,17.88 \%)$, Xianyang (293, 11.03\%), and Baoji (200, 7.56\%); and 2,062 $(77.6 \%)$ cases were reported from 20 affected countylevel jurisdictions and city districts. The Hantavirus carrying rate of rodents as reported by regular surveillance showed no significant changes in rodent population.

Compared with the past five years, the national HFRS prevalence remained low in China (3). As of December 18, 2021, 8,502 cases with 54 (0.63\%) deaths were reported from 29 provincial-level administrative divisions (PLADs), which were $9.10 \%$ and $17.39 \%$ higher than that $(7,793$ cases and 46 deaths) in 2020. The reported cases from top 10 PLADs accounting for $81.6 \%$ of the total reported cases in China. After Shaanxi (2,657 cases), the numbers of cases in Shandong (875 cases), Liaoning (501 cases), Henan (352 cases), Yunnan (295 cases), and Jilin (291 cases) increased by a range from $11.1 \%$ to $76.9 \%$, and the reported number of cases in Heilongjiang (875 cases), Hunan (499 cases), Hubei (396 cases), and Jiangxi (354 cases) decreased from $15.6 \%$ to $31.1 \%$ compared with that in 2020 . Variations of Hantavirus have also previously been found in central and southwest China.

doi: $10.46234 / \mathrm{ccdcw} 2021.272$

\# Corresponding authors: Jiandong Li, lijd@ivdc.chinacdc.cn; Pengbo Yu, sxcdcy@126.com.

\footnotetext{
Center for Disease Control and Prevention of Shaanxi Province, $\mathrm{Xi}^{\prime}$ an, Shaanxi, China; ${ }^{2}$ Institute for Viral Disease Control and Prevention, Chinese Center for Disease Control and Prevention, Beijing, China.

\& Joint first authors.
}

Submitted: December 22, 2021; Accepted: December 23, 2021

\section{REFERENCES}

1. Shang C, Zhang QF, Yin QL, Li DX, Li JD. Influence factors related epidemics on hantavirus disease. Chin J Epidemiol 2020;41(6):968 - 74. http://dx.doi.org/10.3760/cma.j.cn112338-20190916-00678. (In Chinese).

2. Ministry of Health. Handbook of epidemic hemorrhagic fever prevention and control. 2nd ed. Beijing: China People's Health Publishing House. 1998. (In Chinese).

3. Shang C, Sun YW, Yin QL, Huang XX, Liu XS, Zhang QF, et al. Hemorrhagic fever with renal syndrome - Liaoning province, China, 1999-2018. China CDC Wkly 2020;2(20):350 - 4. http://dx.doi.org/ $10.46234 / \mathrm{ccdcw} 2020.091$. 